\title{
Perspectives
}

\section{Possible Role of Anti-Idiotypic Antibodies in the Induction of Tumor Immunity}

\author{
Ronald C. Kennedy, En-Min Zhou, Robert E. Lanford, Tran C. Chanh, and Constantin A. Bona* \\ Department of Virology and Immunology, Southwest Foundation for Biomedical Research, San Antonio, Texas 78284; and \\ *Department of Microbiology, Mount Sinai Medical Center, New York, New York 10029
}

\section{Introduction}

An idiotype (Id), ${ }^{1}$ or idiotypic determinant, is the antigenic portion of an antibody that encompasses the variable (V) region of the molecule. Within the $\mathrm{V}$ region is the site where the antigen specifically binds to the antibody. Early studies by Oudin and Michel (1) and Kunkel and co-workers (2) indicated that an Id was unique to a small set of antibody molecules. However, Ids can also be shared by antibodies specific for a given antigen and are useful as phenotypic $\mathrm{V}$ region antibody gene markers (reviewed in references 3 and 4 ). The Id is often defined by an anti-idiotypic antibody (anti-Id), whereby the Id behaves as an antigen and induces the production of antibodies against itself.

The idea that the immune response to an antigen can be regulated by a series of Id-anti-Id reactions was first proposed by Niels Jerne (5). This network theory of immune regulation proposes that Id-anti-Id reactions control a host's response to an antigen via either a positive (enhancing) or negative (suppressing) feedback mechanism. Id, located on or close to the antigen binding sites of both antibody molecules and lymphocyte antigen receptors, represent components of this network. Numerous studies have implicated Id networks in regulation of the immune response to a large variety of haptens and protein or carbohydrate antigens (reviewed in references 6 and 7). The injection of anti-Id before antigen exposure has resulted in either suppression of Id-positive antigen binding molecules or increased Id expression and antigen binding activity. Numerous reports have suggested the potential use of anti-Id in the induction of protective immunity against a wide variety of infectious agents (8-18). Thus, anti-Ids may represent possi-

Dr. Zhou is a visiting scientist from the People's Republic of China. He is on leave from Bao-Tou Medical College. Address reprint requests to Dr. Kennedy, Department of Virology and Immunology, Southwest Foundation for Biomedical Research, P.O. Box 28147, San Antonio, TX 78284.

Received for publication 21 January 1987 and in revised form 19 June 1987.

1. Abbreviations used in this paper: $\mathrm{Ab}-1$, first antibody produced against a specific antigen; $A b-2$, antibodies to $A b-1$ or anti-Id; $A b-3$, antibodies to $\mathrm{Ab}-2$ or anti-anti-Id; anti-Id, anti-idiotypic antibody; $\mathrm{i}$, conventional idiotope; Id, idiotype; $i_{2}$, conventional idiotope on $\mathrm{Ab}-2$; MMTV, mouse mammary tumor virus; pi, paratope; $p_{2}$, paratope on Ab-2; ri, regulatory idiotope; SV40, simian virus 40; T-ag, large tumor antigen; $V$, variable.

J. Clin. Invest.

(c) The American Society for Clinical Investigation, Inc.

$0021-9738 / 87 / 11 / 1217 / 08 \quad \$ 2.00$

Volume 80, November 1987, 1217-1224 ble vaccine candidates for pathogenic organisms $(19,20)$. Recent studies have demonstrated the efficacy of an anti-Id vaccine for hepatitis B virus in chimpanzees (21). Chimpanzees are the relevant animal model for human hepatitis B virus immunization and infection.

The sites or areas within the $\mathrm{V}$ region of an antibody molecule where the antigen and anti-Id bind have been termed the paratope (pi) and idiotope, respectively. An Id is then made up of a collection of individual idiotopes. If the pi and idiotope are the same sites, then the antigen and anti-Id possess a similar conformation or three-dimensional structure by virtue of their binding to the initial antibody. In this instance the anti-Id and antigen are said to be the mirror or internal image of each other. Immunization with an internal image anti-Id, by virtue of the ability of these antibodies to bind to the pi/idiotope of the immune receptor on lymphocyte clones, instead of antigens, stimulates the expansion of these clones. Therefore, these clones can produce an anti-anti-Id antibody (Ab-3) response with antigen binding activity, since $\mathrm{Ab}-3$ and the original or first antibody produced against a specific antigen (Ab-1) may mimic each other via binding to similar sites encompassing the idiotope and pi on the anti-Id, respectively. This type of response is referred to as a true Ab-3 and appears to represent a minor component of the response to immunization with antiId (22). A second type of response can be induced by anti-Id injection whereby the antibody produced exhibits a different antigen specificity than the initial $\mathrm{Ab}-1$; however, this antibody shares idiotypic specificities with $A b-1$. This response to anti-Id immunization is referred to as an $\mathrm{Ab}-\mathrm{I}^{\prime}$ ( $\mathrm{Ab}-1$ prime). Alternatively, if the pi and idiotope are different regions on the anti-Id, an $\mathrm{Ab}-3$ response can be induced that does not possess antigen binding activity. These two types of $\mathrm{Ab}-3$, which differ in antigen binding activity, may both be involved in the mechanism of regulating the immune response to tumor antigens. The possible role of anti-Id in the induction of tumor immunity will be examined in this report.

\section{Studies of idiotypic networks associated with tumor antigens}

Studies involving Id networks induced by tumor antigens have primarily focused on the use of anti-Id in the treatment of lymphoid tumors. In these studies, cell surface immunoglobulin present on neoplastic B lymphoid cells represented the Id, and suitable anti-Id could eliminate much or all of the tumor, with negligible effects on residual normal tissues (reviewed in references 23 and 24). Passively administered anti-Id can home in on neoplastic cell targets (25-27) and, as was demonstrated in a trial including 11 patients with B cell malignancies, was responsible for sustaining a complete remission in a single patient with follicular lymphoma $(26,27)$. However, other at- 
tempts at passive immunotherapy with anti-Id have been less successful (25). In another report, two patients with progressive advanced B cell non-Hodgkins lymphoma were treated with large amounts of mouse monoclonal anti-Id (28). No toxic effects from treating these patients with mouse immunoglobulin were observed and no antimouse protein response was detected. There was evidence of large scale tumor cell destruction, but only a modest reduction in tumor size. Studies using radiolabeled monoclonal anti-Id indicated that Idbearing tumor cells were cleared from the peripheral blood circulation by the reticuloendothelial system in the liver (29).

Several obstacles have been associated with the lack of therapeutic response by B cell lymphomas after anti-Id treatment. These include applications of anti-Id treatment to only monoclonal malignancies and include multiple myelomas in which Id secreted in the circulation blocks the anti-Id. Furthermore, other causes can be envisioned, such as failure to elicit effective cytotoxicity related to the isotype of the anti-Id, and in human therapy, the production of antibodies against the antigenic determinants of anti-Id, leading to immediate hypersensitivity reactions $(30,31$, and reviewed in reference 24$)$. Recent studies have also indicated that Id present on a B cell lymphoma can spontaneously alter its structure, such that variant subclones of the lymphoma arise that express an Id which is no longer recognized by the anti-Id $(32,33)$. Thus, passive immunotherapy utilizing anti-Id would no longer be expected to detect or potentially eradicate these variant tumors. However, it is not unreasonable to expect that multiple anti-Ids, which recognize the Id variant tumors, might be useful in treating those patients where variant malignant clones arise $(32,33)$. Alternatively, recent studies indicated the synergistic antitumor effect that interferon and anti-Id can have in vivo in a murine lymphoma (34). One can also attempt to select an anti-Id that recognizes a shared Id on B cell tumors from different patients (35). The importance of antibody isotype in monoclonal anti-Id therapy has also been demonstrated in murine B cell lymphoma $(36,37)$. All of these factors may have a potential role in the successful treatment of human $B$ cell lymphomas utilizing anti-Id reagents.

A recent report described the treatment of 13 patients with B cell lymphomas using mouse monoclonal anti-Id (38). Five of these patients developed an immune response to the mouse immunoglobulin. Once this response was induced, further infusion of mouse anti-Id failed to produce tumor regression and toxicity from the mouse immunoglobulin was noted. In one attempt to mimimize the immune response to mouse immunoglobulin when treating patients with lymphoma, a chimeric anti-Id comprising murine $\mathrm{V}$ region and human $\mathrm{Fc}$ regions encompassing a univalent antibody fragment for therapy were used (39). A single patient treated with this univalent chimeric anti-Id has undergone partial remission. The concept behind this approach is that the human Fc optimizes the recruitment of effector cells and the univalency optimizes metabolic survival. Thus, the univalent chimeric anti-Id can avoid rapid antigenic modulation.

\section{Internal image-bearing anti-Id mimics the structure of tumor antigens}

The complementarity between antigen and antibody and Id and anti-Id was discussed above. When the pi and idiotope of the antibody represent the same or similar regions, the antigen and anti-Id should be the mirror or internal image of each other by virtue of the ability to bind to their respective sites on the initial antibody. Even though the antigen and anti-Id may be completely different biochemically, they share a similar three-dimensional structure that allows for the binding to paratopic and idiotopic sites on the antibody (Ab-1), respectively. It then becomes possible to use the anti-Id for antigen mimicry and trigger the host's immune response into producing a humoral or cell-mediated antigen-specific immune response by injecting anti-Id alone. Anti-Id that represents the internal image of an antigen should be useful in inducing an immune response without exposing the host to the antigen. When this antigen is associated with the surface of a tumor cell, the internal image anti-Id should be capable of inducing antitumor immunity similar to that produced by tumor antigen injection $(40,41)$. The means by which internal image anti-Id can produce a specific antibody response to a tumor antigen is depicted in Fig. 1.

Numerous studies have previously demonstrated the applicability of anti-Id as vaccines for infectious agents (reviewed in reference 20 ). Anti-Id injection alone has produced immunity against antigens associated with bacterial, viral, and protozoal pathogens. In addition, anti-Id has been shown to prime the immune response of a host to a subsequent injection with the antigen from an infectious agent $(10,42)$. Internal image antiId can cross species barriers in their ability to induce an immune response and have been reported to be less genetically restricted to certain murine immune response genes than the specific antigen itself $(43,44)$. Anti-Id produced against an antibody specific for the antigen can induce a cell-mediated immune response (11) and anti-Id generated to antigen-specific $\mathrm{T}$ cell clones was capable of producing a humoral response (13). Anti-Id are extremely valuable as vaccine candidates when there is difficulty in obtaining adequate amounts of the antigen. This is particularly true with most tumor antigen systems. A pool of internal image anti-Id may be required for producing adequate immunity against complex, multi-determinant antigens, such as those associated with tumors.

The studies describing anti-Id generated to immunoglobulin Id present on the surface of a lymphoid tumor relied on the ability of the anti-Id to bind to the tumor antigen after the transformed phenotype of the cell had already occurred. Alternatively, the anti-Id can be used to mimic the tumor antigen structure and produce antitumor immunity before either malignant transformation within host tissues or inoculation of a host with transformed cells. Indeed, injection of mice with anti-Id that appears to mimic the tumor antigen structure has been reported to induce antitumor immunity in human melanoma (45), mammary adenocarcinoma (46), and rat sarcoma (47). Recently, anti-Id has been produced in goats that contains antibody components that mimic human gastrointestinal cancer-associated antigens (40). Mice and rabbits were immunized with this anti-Id and produced an Ab-3 response that bound the human tumor antigen. The Ab-3 demonstrated identical binding specificities and avidity to the tumor antigen when compared with the initial mouse monoclonal Ab-1 that was used to produce the anti-Id. This study indicated that anti-Id may have potential for modulating the immune response of cancer patients to their tumors. The concept of tumor-specific Id vaccines has also been experimentally demonstrated in mice (41). Mouse monoclonal anti-Id were gener- 


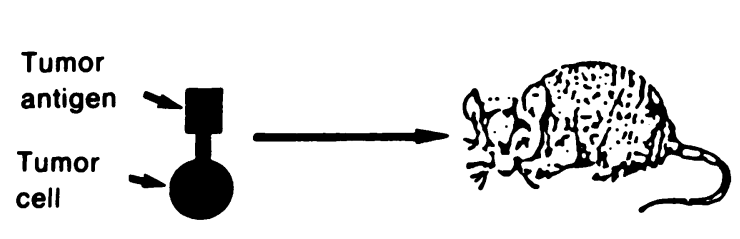

The tumor cell is injected into a mouse.

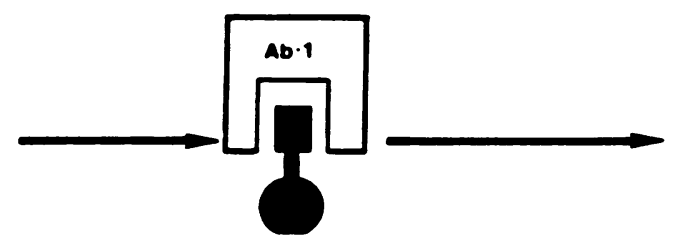

An antibody $(\mathrm{Ab}-1)$ that binds to the tumor antigen.

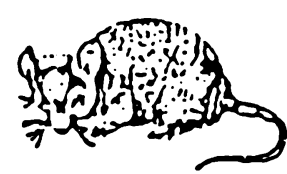

$A b-1$ is injected into a second mouse...

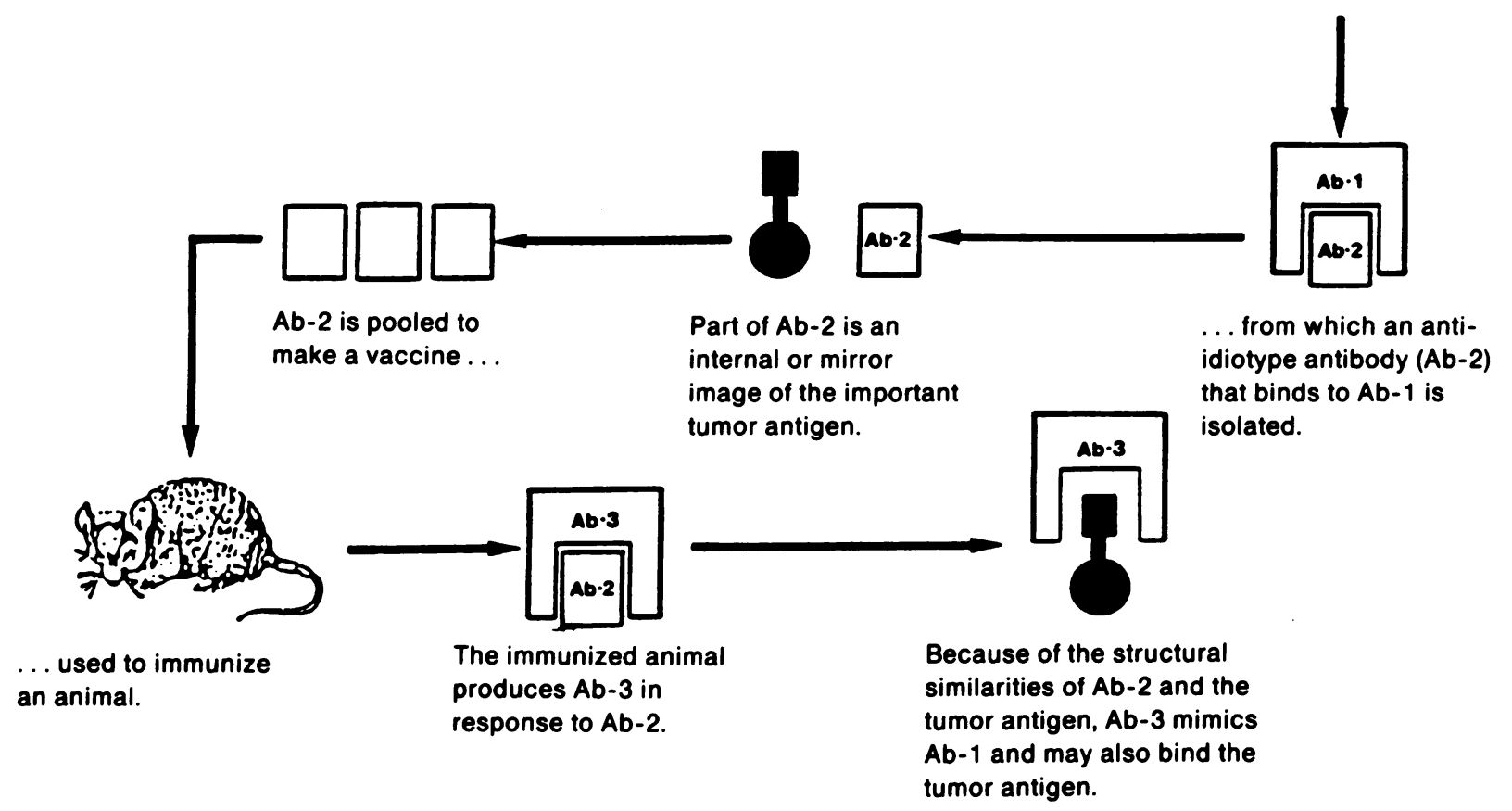

Figure 1. The potential mechanism of how an internal image anti-Id might mimic a tumor antigen and represent a vaccine. A host, such as a mouse, produces an antibody response (Ab-1) against the tumor. The Ab-1 is then used to immunize a second host and an anti-Ab-1 or $-\mathrm{Ab}-2$ response can be induced. Based on the concept that the tumor antigen and $\mathrm{Ab}-2$ bind the $\mathrm{Ab}-1$ at its pi and idiotope, respectively, and these sites on the Ab-1 can be the same or similar, the

ated that contained the internal image of the envelope glycoprotein, gp52, of mouse mammary tumor virus (MMTV). It was interesting to demonstrate that the protein-based anti-Id could mimick the structure of the MMTV envelope glycoprotein even though biochemically the two molecules were different. Mice immunized with anti-Id coupled to a carrier protein had the capacity to inhibit in vivo tumor growth after challenge with a tumor cell line expressing a tumor-associated antigen that crossreacts with MMTV, gp52. In addition, anti-Idimmunized mice produce an antibody response to MMTV before tumor challenge. This study demonstrated the feasibility of producing an anti-Id that could be exploited as an Id vaccine against tumors.

Other studies have demonstrated that anti-Id treatment can have either advantageous or deleterious effects on the immune response to a given tumor depending on the system being examined. Anti-Id generated against suppressor T lymphocyte receptors has been shown to reduce the in vivo tumor growth of a mastocytoma (48), whereas another report indicated that anti-Id suppressed tumor rejection to fibrosarcoma

$\mathrm{Ab}-2$ can mimic the structure of the tumor antigen. Such an Ab-2 is referred to as an internal image anti-Id and can be used as a substitute for the tumor antigen. The $A b-2$ is the vaccine and can be used to immunize a host to produce an Ab-3. The Ab-3 can mimic the $\mathrm{Ab}-1$ and bind the tumor antigen. In certain instances where multideterminant antigens are required for the induction of protective immunity, a pool of several Ab-2 may be used as the vaccine.

when produced against $T$ lymphocyte clones (49). Anti-Id has also been implicated in the clinical improvement and longer remission of patients with colorectal carcinoma who were injected with mouse monoclonal antibodies against these gastrointestinal cancer cells (50). In a phase II clinical trial, the therapeutic effect of the monoclonal antibody that demonstrated in vitro cytotoxicity for human gastrointestinal adenocarcinomas was assessed (51). 20 patients with measurable advanced colorectal carcinoma that was refractory to prior surgical resection, chemotherapy, and/or radiotherapy received the monoclonal antibody. In one patient, tumor at all known sites responded after a single injection of antibody. Another patient demonstrated a marked reduction in hepatic metastasis and in a third patient stabilization of tumor growth persisted. 2 of the 20 patients have remained tumor free for more than two years and the clinical improvement of these patients appeared to correlate with the production of an anti-Id response. The data described above indicated that Id networks may play some integral immunological role in the formation of tumors, via regulating the immune response to tumor antigens. 


\section{Regulatory idiotopes (ri) in the induction} of tumor immunity

An ri is an idiotope that is present on a relatively high proportion of antibodies and/or lymphocytes that is capable of acting as a site for a receptor-specific regulatory system. This concept, initially proposed by Paul and Bona (52), suggests that a special class of idiotopes exist with unique regulatory functions before antigenic stimulation. Numerous studies have implicated ri as a model for receptor-based regulation of the immune response, in that a given ri can be associated with cells producing antibodies of different specificities (reviewed in reference 53). Therefore, a given antibody molecule can possess paratopic (pi), idiotopic, and ri sites within its $\mathrm{V}$ region. During the course of a conventional immune response, it is hypothesized that no ri are recognized on antibody and/or lymphocytes, and the Id network consists of only an antibody response to the conventional idiotope (i). Internal image antiId appear to possess only pi and idiotope sites as either no ri are expressed or they are present at concentrations too low to be immunogenic. The injection of internal image anti-Id can induce an Ab-3 response with antigen binding activity. This anti-Id has a pi site that is specific for a conventional idiotope on $\mathrm{Ab}-1$. Therefore, immunization with the internal image antibodies to Ab-1 or anti-Id (Ab-2) specific for the conventional idiotope induces a family of $\mathrm{Ab}-1$, including so called true $\mathrm{Ab}-3$, that possess the ability to bind the anti-Id and antigen (see Fig. 1). Similarly, a noninternal image anti-Id Ab-2 may also express only a paratope on $\mathrm{Ab}-2\left(\mathrm{p}_{2}\right)$ and conventional idiotope on Ab-2 $\left(i_{2}\right)$. However, the $p_{2}$ on noninternal image $A b-2$ may be specific for a ri on $A b-1$, rather than a conventional idiotope. Immunization of a host with a noninternal image anti-id should lead to the expansion of cells bearing complementary receptors (i.e., contain pi, i, and ri). By definition, $r i$ are widely represented in a system before intentional immunization. Injection with a noninternal image $\mathrm{Ab}-2$ should further stimulate these ri-expressing cells. An Ab-3 response will subsequently be produced that generally has little binding specificity for the antigen that induced $\mathrm{Ab}-1$ because similar ri can be expressed on cells that have a pi similar to $\mathrm{Ab}-1$ are primed by this noninternal image $\mathrm{Ab}-2$ immunization. If these ri-bearing cells with pi sites specific for the antigen used to produce Ab-1 are important in the induction of protective immunity, then primary challenge with an infectious inoculum might be expected to produce a secondary immune response within the host. This would result from the priming of pi-, i-, and ri-bearing cells by the anti-Id before challenge. The potential mechanism of ri-based pathways is illustrated in Fig. 2.

Experimental evidence for the role of ri in tumor immunity Recently, we have generated anti-Id reagents against simian virus 40 (SV40) large tumor antigen (T-ag) (54). SV40 is an oncogenic DNA virus that induces tumors in vivo when inoculated into newborn hamsters and transforms cells in vitro from a variety of species, including rodents, primates, and humans. Rodent cells transformed by SV40 in vitro will frequently form tumors in hamsters and mice (reviewed in reference 55). Cells that have been transformed by SV40 express a viral-encoded T-ag. T-ag is predominantly localized in the nucleus of transformed cells; however, a small fraction of $\mathrm{T}$-ag is found on the cell surface (56-60). Mice immunized against $T$-ag are protected from challenge by syngeneic SV40 tumor cells (61-64, and reviewed in reference 65). Thus, the SV40 T-ag is associated with the induction of tumor immunity. Treatment of BALB/c mice with a pool of anti-Id generated to monoclonal antibodies to both the carboxyl and amino termini of SV40 T-ag before challenge with a tumorigenic dose of SV40transformed cells partially suppressed tumor growth (51). In certain cases the suppression was complete, since several antiId-treated mice failed to develop any detectable tumors after challenge. In these instances, $100 \%$ of the control groups of mice developed tumors. We examined the potential mechanism of this anti-Id-induced tumor immunity and determined that the anti-Id preparation did not contain a major internal image component mimicking SV40 T-ag. That is, no detectable anti-T-ag activity was found in the serum of anti-Idtreated mice. However, this sera inhibited the Id-anti-Id reaction and indicated that an $\mathrm{Ab}-3$ response was induced by antiId injection. Since this Ab-3 did not appear to contain any detectable anti-T-ag activity, it was proposed that the anti-Idinduced SV40 tumor suppression may have resulted from the induction of ri. In the mechanism that was described above, anti-Id (Ab-2) that is not internal image, but contains both noncombining site-related $\mathrm{Ab}-2 \alpha$ and combining site-related $\mathrm{Ab}-2 \gamma$ induces the generation of an $\mathrm{Ab}-3$ response that expresses similar ri as those shared by $\mathrm{Ab}-1$ (i.e., inhibits Idanti-Id reaction). These $\mathrm{Ab}-3$ are not capable of binding to the original antigen, in this case $\mathrm{T}-\mathrm{ag}$, like their $\mathrm{Ab}-1$ counterparts; however, they do possess the Id determinants of $\mathrm{Ab}-1$. This set of Ab-3 molecules may exert effects via their ability to stimulate or suppress either effector or inducer cells within a regulatory subset of the network, which has been referred to as the parallel set (5). These stimulated or suppressed cells that comprise the parallel set of the immune network can function by exerting regulatory effects on the immune system cells directly responsible for the induction of tumor immunity (the conventional network induced by SV40-transformed cells). It is proposed that the parallel set of effector/inducer ( $T$ suppressor/ cytotoxic or $\mathrm{T}$ helper) cells have Ab-2-like receptors on their cell surfaces. The production of $\mathrm{Ab}-3$ by anti-Id immunization induces the regulatory $\mathrm{Ab}-2$-bearing cells to proliferate and induce or suppress other effector/inducer cells responsible for SV40 tumor immunity. Under normal circumstances (without prior injection of anti-Id), the regulatory cells comprising the parallel set may not be stimulated and therefore have no effect directly on the cells responsible for SV40 tumor immunity. Thus, the parallel subset of the immune system may only exert its specific effects in SV40 tumor immunity after $\mathrm{Ab}-3$ production. Alternatively, during the course of tumor formation, a putative idiotype network may be generated such that Ab-3 is produced and may stimulate $A b-2$ receptor-bearing parallel subsets of regulatory cells. However, by the time an auto Ab-3 response is produced, the growth of the tumor can no longer be suppressed by induction of $\mathrm{Ab}-2$-bearing regulatory cells. The injection of a heterologous anti-Id before tumor challenge may prime or stimulate the regulatory cells at a time when the number of SV40-transformed cells is low and the effects of these regulatory functions can suppress tumor formation. The potential mechanism for the induction of ri that suppress SV40 tumor formation is illustrated in Fig. 3. Based on these data, ri may indeed play a potential role in the induction of tumor immunity. 
Figure 2. A hypothesis on how ri may be involved in tumor immunity. A tumor antigen is injected into a host and an antibody response is induced. This Ab-1 can contain a pi where the antigen binds, a conventional idiotope to which most Ab-2 responses including potentially internal image anti-Id can be induced, and an ri that does not necessarily reflect the antigen specificity of the Ab-1 and is normally not recognized during an immune response. If an immune response is invoked against the ri on $A b-1$, then the $A b-2$ has a pi structure that binds the ri site on the Ab-1. As depicted in this figure, the Ab-2 contains $a p_{2}$ and an $i_{2}$. This $\mathrm{Ab}-2$ is not an internal image since its $i_{2}$ fails to mimic the structure of the tumor antigen. Immunization with this Ab-2 will result in the expansion of cells that share the ri with the Ab-1. By definition, ri are widely expressed and will include some cells that also have a similar pi and $i$ to the Ab-1 with the capacity to bind the tumor antigen. Alternatively, cells will also be expanded that share an ri with the Ab-1 but may differ in $i$ and pi. This expansion would result in an Ab-3 response that has little or no binding specificity for the tumor antigen. The expansion of cells that share a pi and $\mathrm{i}$ with the Ab-1 by an anti-Id that recognizes the ri would be expected to prime the immune response to the tumor antigen.

In another study, the question was asked whether or not all antibodies bearing ri are effective in antitumor immunity. The system being studied used numerous monoclonal antibodies bearing A48 ri and used their ability to induce immunity against ABPC 48 myeloma cells (66). BALB/c mice were immunized with monoclonal antibodies before challenge with $10^{6}$ ABPC 48 tumor cells that had been previously adapted to home and grow into the spleen. The criteria used to monitor tumor growth were ( $a$ ) survival; $(b)$ spleen weight; (c) uptake of $\left[{ }^{3} \mathrm{H}\right]$ thymidine, and $(d)$ the blood level of a $\beta$ 2-6 fructosan IgA monoclonal protein secreted by ABPC 48 myeloma cells. Four patterns of immunity were observed. The first group that comprised three monoclonal antibodies failed to elicit any tumor immunity and all mice died. The second group, consisting of two monoclonal antibodies, showed a slight increase in survival time ( $>30 \mathrm{~d}$ ) compared with the first group (21-24 d). The third group, containing four monoclonal antibodies, induced strong immunity (40-50 d survival), and group 4, comprising five monoclonal antibodies, caused long-lasting immunity ( $>95 \mathrm{~d}$ survival). This immunity was specific, since the mice immunized with a control myeloma cell line MOPC 460 died by day 21 . In addition, mice immunized with antibodies from group 4 and challenged with control tumor cells developed splenic tumor colonies. These results suggest that not all antibodies bearing immunochemically and molecularly defined ri are able to confer antitumor immunity. However, the identification of idiotypic structures responsible for antitumor immunity can open new avenues in the preparation of tumor idiotype synthetic vaccines.

\section{Concluding remarks}

Since the initial postulate of Jerne that the immune response to an antigen is regulated by a series of Id-anti-Id reactions (5), numerous studies have demonstrated that Id networks operate in regulating the immune response to a wide variety of antigens, including those antigens associated with infectious organisms. Although the data is still not conclusive that Id networks may be involved in tumor immunity, based on other 


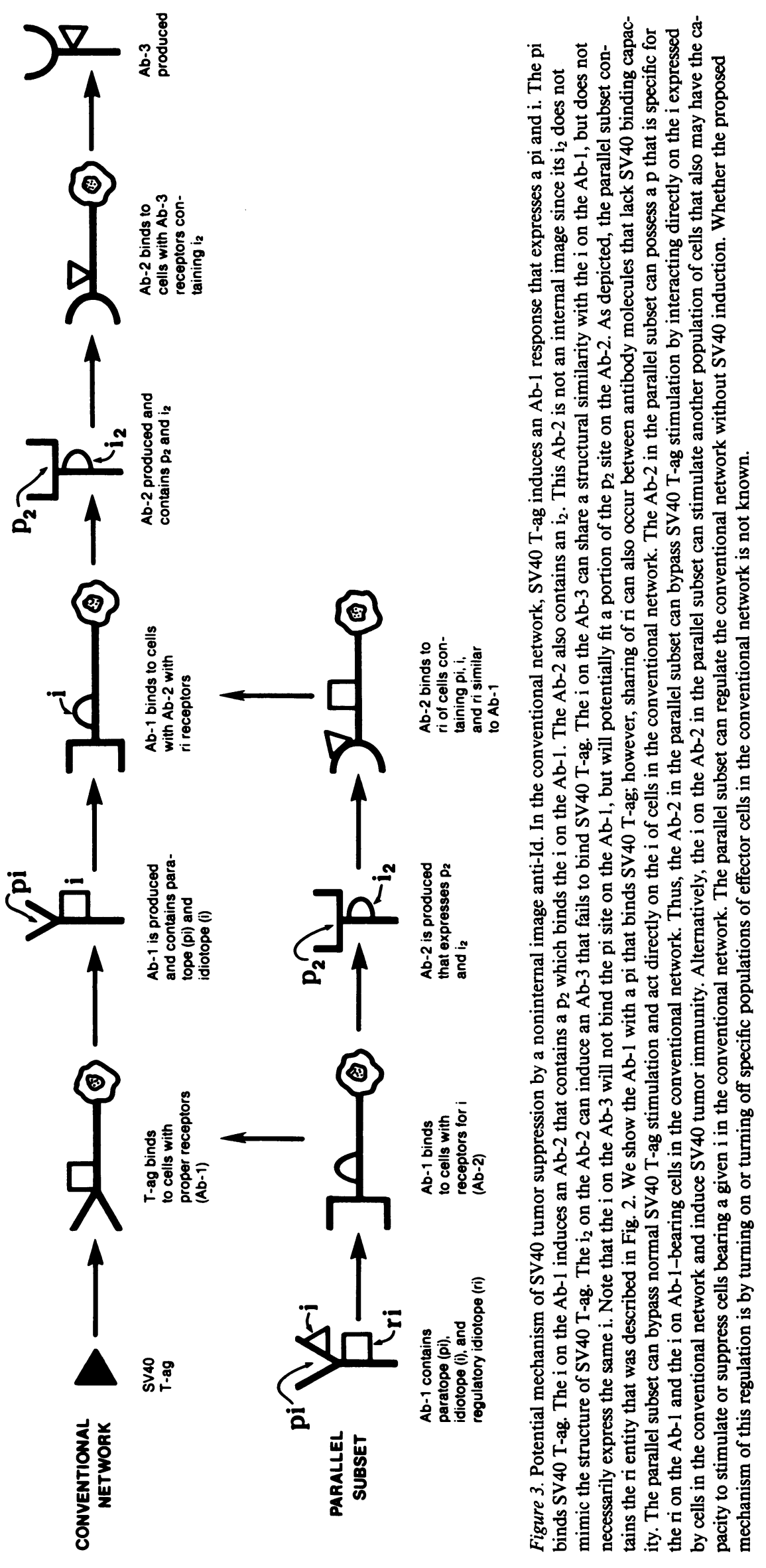


antigenic systems it is not unreasonable to speculate that Idanti-Id reactions may modulate the immune response to certain tumor antigens. We have attempted to present two different mechanisms by which Id networks may be involved in tumor immunity. The first mechanism was that of antigenic mimicry by internal image anti-Id. Studies have demonstrated the possible role of internal image anti-Id as vaccines for infectious diseases and recently for tumors. Alternatively, the mechanism of regulatory idiotopes as a regulator of tumor immunity was also described. Evidence that this mechanism may be involved in the suppression of tumor formation was suggested by studies using rabbit anti-Id that recognized mouse monoclonal antibodies specific for SV40 T-ag and the ABPC48 myeloma cell system. In addition, the possibility exists that passively administered mouse monoclonal anti-Id specific for Id determinants on lymphomas may induce a regulatory idiotope pathway that could either enhance or depress the therapeutic value of this treatment in a given host. With the number of reports increasing on the use of anti-Id to treat human neoplasia, one should be aware of the possibility of invoking an immune response to regulatory idiotypes. This report discusses the possible role of anti-Id and Id networks in the induction of tumor immunity.

\section{Acknowledgments}

This work was supported by New Investigator Research Award 1R23 AI-22307-01 from the National Institute of Allergy and Infectious Diseases, grant CA39390 from the National Cancer Institute, and by a grant from the Southwest Foundation Forum.

\section{References}

1. Oudin, J., and M. Michel. 1963. C. R. Hebd. Seances Acad. Sci. 257:805-808.

2. Kunkel, H. G., M. Mannik, and R. C. Williams. 1963. Science (Wash. DC). 140:1218-1219.

3. Eichmann, K. 1975. Immunogenetics. 2:491-506.

4. Weigert, M., and M. Potter. 1977. Immunogenetics. 4:401-435.

5. Jerne, N. K. 1974. Ann. Immunol. (Paris). 125c:373-389.

6. Bona, C. A., and H. Kohler, editors. 1983. Ann. NY Acad. Sci. 418:1-395.

7. Rodkey, L. S. 1980. Microbiol. Rev. 44:631-659.

8. Sacks, D. L., K. M. Esser, and A. Sher. 1982. J. Exp. Med. 155:1108-1119.

9. Kennedy, R. C., K. Adler-Storthz, R. D. Henkel, Y. Sanchez, J. L. Melnick, and G. R. Dreesman. 1983. Science (Wash. DC). 221:853-855.

10. Reagan, K. J., W. H. Wunner, T. J. Wiktor, and H. Koprowski. 1983. J. Virol. 48:660-666.

11. Sharpe, A. H., G. N. Gaulton, K. K. McDade, B. N. Fields, and M. I. Greene. 1984. J. Exp. Med. 160:1195-1205.

12. Kennedy, R. C., and G. R. Dreesman. 1984. J. Exp. Med. 159:655-665.

13. Ertl, H. C. J., and R. W. Finberg. 1984. Proc. Natl. Acad. Sci. USA. 81:2850-2854.

14. McNamara, M. K., R. E. Ward, and H. Kohler. 1984. Science (Wash. DC). 226:1325-1326.

15. Stein, K. E., and T. Soderstrom. 1984. J. Exp. Med. 160:10011011.

16. Uytdehaag, F. G. C. M., and A. D. M. E. Osterhaus. 1985. J. Immunol. 134:1225-1229.

17. Kaufmann, S. H. E., K. Eichmann, I. Muller, and L. J. Wrazel. 1985. J. Immunol. 134:4123-4127.
18. Gell, P. G. H., and P. A. H. Moss. 1985. J. Gen. Virol. 66:1801-1804.

19. Nisonoff, A., and E. Lamoyi. 1981. Clin. Immunol. Immunopathol. 21:397-406.

20. Dreesman, G. R., and R. C. Kennedy. 1985. J. Infect. Dis. 151:761-765.

21. Kennedy, R. C., J. W. Eichberg, R. E. Lanford, and G. R. Dreesman. 1986. Science (Wash. DC). 232:220-223.

22. Victor-Kobrin, C., F. A. Bonilla, B. Bellon, and C. A. Bona. 1985. J. Exp. Med. 162:647-662.

23. Krolick, K. A., P. C. Isakson, J. W. Uhr, and E. S. Vitetta. 1979. Immunol. Rev. 48:81-106.

24. Stevenson, G. T., and F. K. Stevenson. 1983. Springer Semin. Immunopathol. 6:99-115.

25. Hamblin, T. J., A. K. Abdul-Ahad, J. Gordon, F. K. Stevenson, and G. T. Stevenson. 1980. Br. J. Cancer. 42:495-502.

26. Miller, R. A., D. G. Maloney, R. Warnke, and R. Levy. 1982. N. Engl. J. Med. 306:517-522.

27. Meeker, T., J. Lowder, D. G. Maloney, R. A. Miller, K. Thielemans, R. Warnke, and R. Levy. 1985. Blood. 65:1349-1363.

28. Rankin, E. M., A. Hekman, R. Somers, and ten Bokkel Huinink. 1985. Blood. 65:1373-1381.

29. Rankin, E. M., A. Hekman, M. R. Hardeman, and C. A. Hoefnagel. 1984. Br. Med. J. 289:1097-1100.

30. Ritz, J., J. M. Pesando, J. Notis-McConarty, and S. F. Schlossman. 1980. J. Immunol. 125:1506-1514.

31. Sklar, J., M. L. Cleary, K. Thielemans, J. Grawlow, R. Warnke, and R. Levy. 1984. N. Engl. J. Med. 311:20-27.

32. Meeker, T., J. Lowder, M. L. Cleary, S. Stewart, R. Warnke, J. Sklar, and R. Levy. 1985. N. Engl. J. Med. 312:1658-1665.

33. Raffeld, M., L. Neckers, D. L. Longo, and J. Cossman. 1985. $N$. Engl. J. Med. 312:1653-1658.

34. Basham, T. Y., M. S. Kaminski, K. Kitamura, R. Levy, and T. C. Merrigen. 1986. J. Immunol. 137:3019-3024.

35. Stevenson, F. K., M. Wrightham, M. J. Glennie, D. B. Jones, A. R. Catten, T. Feizi, T. J. Hamblin, and G. T. Stevenson. 1986. Blood. 68:430-436.

36. Kaminski, M. S., K. Kitamura, D. G. Maloney, M. J. Campbell, and R. Levy. 1986. J. Immunol. 136:1123-1130.

37. Kodama, K., V. K. Ghanta, R. N. Hiramoto, R. C. Stohrer, and J. F. Kearney. 1986. Cancer Res. 46:1260-1254.

38. Miller, R. A., J. Lowder, T. C. Meeker, S. Brown, and R. Levy. 1987. NCI Monographs. 3:131-134.

39. Hamblin, T. J., A. R. Cattan, M. J. Glennie, M. R. MacKenzie, F. K. Stevenson, H. F. Watts, and G. T. Stevenson. 1987. Blood. 69:790-797.

40. Herlyn, D., A. H. Ross, and H. Koprowski. 1986. Science (Wash. DC). 232:100-104.

41. Raychaudhuri, S., Y. Saeki, H. Fuji, and H. Kohler. 1986. J. Immunol. 137:1743-1749.

42. Kennedy, R. C., J. T. Sparrow, Y. Sanchez, J. L. Melnick, and G. R. Dreesman. 1984. Virology. 136:247-252.

43. Ertl, H. C. J., E. Homans, S. Tournas, and R. W. Finberg. 1984. J. Exp. Med. 159:1778-1783.

13.

44. Kennedy, R. C. 1985. Curr. Top. Microbiol. Immunol. 119:1-

45. Nepom, G. T., K. A. Nelson, S. L. Holbeck, I. Hellstrom, and

K. E. Hellstrom. 1984. Proc. Natl. Acad. Sci. USA. 81:2864-2867.

46. Gorczynski, R. M., M. Kennedy, I. Polidoulis, and G. B. Price.

1984. Cancer Res. 44:3291-3298.

47. Dunn, P. L., C. A. Johnson, J. M. Styles, S. S. Pease, and C. J. Dean. 1987. Immunology. 60:181-186.

48. Tilkin, A. F., N. Schaaf-Lafontaine, A. Van Acker, M. Boccadoro, and J. Urbain. 1981. Proc. Natl. Acad. Sci. USA. 78:1809-1812.

49. Flood, P. M., M. L. Kripke, D. A. Rowley, and H. Schreiber. 1980. Proc. Natl. Acad. Sci. USA. 77:2209-2213. 
50. Koprowski, H., D. Herlyn, M. Lubeck, E. DeFrietas, and H. F. Sears. 1984. Proc. Natl. Acad. Sci. USA. 81:216-219.

51. Sears, H. F., D. Herlyn, Z. Steplewski, and H. Koprowski. 1985. Cancer Res. 45:5910-5913.

52. Paul, W. E., and C. Bona. 1982. Immunol. Today. 3:230-234.

53. Bona, C. A., C. Victor-Kobrin, A. J. Manheimer, B. Bellon, and L. J. Rubinstein. 1984. Immunol. Rev. 79:25-44.

54. Kennedy, R. C., G. R. Dreesman, J. S. Butel, and R. E. Lanford. 1985. J. Exp. Med. 161:1432-1449.

55. Butel, J. S., S. S. Tevethia, and J. L. Melnick. 1972. Adv. Cancer Res. 15:1-55.

56. Rapp, F., J. S. Butel, and J. L. Melnick. 1964. Proc. Soc. Exp. Biol. Med. 116:1131-1135.

57. Soule, H. R., and J. S. Butel. 1979. J. Virol. 30:523-532.
58. Lanford, R. E., and J. S. Butel. 1979. Virology. 97:295-306. 59. Soule, H. R., R. E. Lanford, and J. S. Butel. 1980. J. Virol. 33:887-901.

60. Deppert, W., K. Hanke, and R. Henning. 1980. J. Virol. 35:505-518.

61. Luborsky, S. W., C. Chang, S. J. Pancake, and P. T. Mora. 1978. Cancer Res. 38:2367-2371.

62. Anderson, J. L., R. G. Martin, C. Chang, P. T. Mora, and D. M. Livingston. 1977. Virology. 76:420-425.

63. Chang, C., R. G. Martin, D. M. Livingston, S. W. Luborsky, C.-P. Hu, and P. T. Mora. 1979. J. Virol. 29:69-75.

64. Flyer, D. C., and S. S. Tevethia. 1982. Virology. 117:267-270. 65. Tevethia, S. S. 1980. Immunology of simian virus 40. In Viral Oncology. G. Klein, editor. Raven Press, New York. 581-601.

66. Rubinstein, L. J., and C. A. Bona. Cancer Res. 46:1603-1607. 